Current Topics: Current

Status and Future Perspective

on the Application of Host

Defense Peptides to Medicine

Juntendo Medical Journal

2016. 62 (2), 120-131

\title{
Novel Insight Into the Role of Antimicrobial (Host Defense) Peptides/Proteins in Human Skin Diseases
}

\author{
FRANÇOIS NIYONSABA*1) 2) \\ *1) Faculty of International Liberal Arts, Juntendo University, Tokyo, Japan, *2) Atopy (Allergy) Research Center, Juntendo \\ University Graduate School of Medicine, Tokyo, Japan
}

In addition to functioning as a physical barrier, the skin has evolved several innate defense mechanisms for the rapid recognition of and protection against harmful microorganisms. As a part of this process, the skin releases a vast and powerful arsenal of antimicrobial peptides/proteins (AMPs), also called host defense peptides/proteins (HDPs), which are key players in the cutaneous immune system. Although originally named antimicrobial peptides, recent evidence has demonstrated that AMPs/HDPs play additional roles in orchestrating the adaptive immune response, such as the regulation of inflammation, induction of cell proliferation and differentiation, regulation of cytokine/chemokine production, facilitation of cell migration, promotion of wound healing and regulation of tight junction barriers. Additionally, numerous skin diseases show altered expression of AMPs/HDPs in the lesional skin, suggesting the crucial roles of these molecules in the pathophysiology of skin diseases. The purpose of this review is to describe the current knowledge regarding some of the most common and well-known AMPs/HDPs derived from the skin, to discuss the regulation of their expression and their antimicrobial and immunomodulatory functions, and to outline their roles in various skin diseases. We believe that understanding the basic knowledge of skin-derived AMPs/HDPs would provide new insight into the pathophysiology of skin disorders and offer novel therapeutic opportunities for skin infectious diseases.

Key words: antimicrobial (host defense) peptide/protein, keratinocyte, skin disease, skin immunity, therapeutic agent

\section{Introduction}

The human skin is continuously exposed to external threats, although the infection rate remains low. This low infection rate is in part attributed to the fact that the skin protects the body from harmful factors through the combination of physical and chemical barrier properties, including its structural integrity, slight acidic $\mathrm{pH}$, and secretion of various cytokines and chemokines ${ }^{1}$. Furthermore, as an antimicrobial barrier, resident and infiltrating cells in the skin such as keratinocytes, phagocytes and mast cells are able to generate a number of small powerful molecules called antimicrobial peptides (AMPs), which are generally short (10-50 amino acids in length), typically having a net positive charge as a result of excess lysine and arginine residues ${ }^{12}{ }^{2}$. AMPs are able to fold into amphiphilic structures and provide a rapid, direct but non-specific first-line chemical shield in innate immunity by killing a broad spectrum of bacteria, fungi, and viruses ${ }^{12}{ }^{2}$. In

\footnotetext{
François Niyonsaba

Atopy (Allergy) Research Center and Faculty of International Liberal Arts, Juntendo University,

2-1-1 Hongo, Bunkyo-ku, Tokyo 113-8421, Japan

TEL: +81-3-5802-1591 FAX: +81-3-3813-5512 E-mail: francois@juntendo.ac.jp

〔Received Mar. 14, 2016〕
}

Copyright (C) 2016 The Juntendo Medical Society. This is an open access article distributed under the terms of Creative Commons Attribution License (CC BY), which permits unrestricted use, distribution, and reproduction in any medium, provided the original source is properly credited. doi: $10.14789 /$ jmj. 62.120 
addition to their killing properties, there is irrefutable evidence that AMPs also play major roles in immunomodulation. For example, AMPs control host patho-physiological functions such as cell migration, proliferation, differentiation, apoptosis, production of cytokines and chemokines, angiogenesis and wound healing ${ }^{1)}{ }^{2}$. Accordingly, the term "antimicrobial" is actually a bit of a misnomer and is misleading because it describes more about the history of discovery rather than the major functions of these peptides. Therefore, alternative names such as host defense peptide (HDP) or alarmin have been recently suggested ${ }^{3)}{ }^{4}$. In this review, the term AMP/HDP will be used throughout the entire text to appreciate both the history of the discovery and the functions of these peptides/proteins.

To date, more than 2,300 AMPs/HDPs from different origins including bacteria, plants, reptiles and mammals have been reported in the AMP database (http://aps.unmc.edu/AP/main.php). Human AMPs/ HDPs have been detected in several cell types and tissues, including the skin, mucosa of airways, gastro-intestine and genito-urinary ducts ${ }^{1)}{ }^{2)}$. In the human skin, several hundred AMPs/HDPs have been discovered and are expressed constitutively or inducibly in response to dangerous situations such as skin injury, infection and chronic inflammation. Recent reports have shown the close association between altered expression of AMPs/ HDPs and various human diseases. For example, AMPs/HDPs have been demonstrated to play intriguing roles in many skin disorders such as psoriasis, atopic dermatitis (AD), rosacea, wound healing, burns and other conditions ${ }^{1)}{ }^{2)}$.

In this review, we discuss some potentially important AMPs/HDPs and their contribution to human skin infectious diseases. These AMPs/HDPs include, but not limited to human $\beta$-defensins (hBDs), cathelicidin LL-37 and S100 proteins. We also summarize a number of AMPs/HDPs or their derivatives that might have clinical potential for the treatment of skin diseases.

\section{AMPs/HDPs in human skin}

\section{Human $\beta$-defensins (hBDs)}

Human defensins are group of AMPs/HDPs characterized by the presence of six conserved cysteine residues that form three pairs of intramo- lecular disulfide bridges. Defensins are classified into $\alpha^{-}, \beta^{-}$, and $\theta$-defensins based upon their typical spaces between the cysteine residues and their disulfide alignment ${ }^{5)}{ }^{6}$. In humans, $6 \alpha$-defensins have been identified: human neutrophil peptide (HNP) -1 to -4 that are found in the azurophilic granules of neutrophils ${ }^{7)}$, and human defensin (HD) -5 and -6 that are abundantly expressed in the Paneth cells of the small intestine ${ }^{8)}{ }^{9)}$. The $\theta$-defensins are found in the neutrophils of "old world" non-human primates such as the gorilla and chimpanzee, but have not been identified in humans ${ }^{10)}$. To date, six different hBDs have been identified and characterized in humans. hBD -1 to -4 are predominantly found in the epithelia, including the epidermis of skin, respiratory and urogenital tracts, and $\mathrm{hBD}-5$ and $\mathrm{hBD}^{-6}$ are specifically detected in the epididymis ${ }^{1{ }^{2}}{ }^{2}$. $\mathrm{hBD}-1$ is constitutively expressed in the skin epidermis, sweat ducts and sebaceous glands and could also be inducible by pathogen-derived molecules such as lipopolysaccharide (LPS) and peptidoglycan ${ }^{11}$. Conversely, the expression of hBD-2 to -4 is mostly inducible following wound healing, infection and inflammation ${ }^{12)}$. Inducers of hBD-2, -3 and -4 include T-helper (Th) 1- and Th17-derived pro-inflammatory cytokines such as interleukin (IL) $-1 \alpha$ and $-1 \beta$, IL-17A, IL-22, tumor necrosis factor (TNF) $-\alpha$ and interferon $(\mathrm{IFN})-\gamma$. Other strong inducers of hBDs include growth factors such as insulin-like growth factor-1 (IGF-1) and transforming growth factor $-\alpha(\mathrm{TGF}-\alpha)$, bacteria and microbial products ${ }^{1)}{ }^{2}$. Higher levels of hBD- 1 and hBD- 2 are detected in the differentiated layers of the epidermis compared with the basal layers. hBD-2 is stored in the lamellar bodies and is secreted to the stratum corneum - stratum granulosum junctions ${ }^{12)}{ }^{13)}$. In contrast to hBD- 1 and $\mathrm{hBD}-2, \mathrm{hBD}-3$ is found in the epithelia and is also abundantly present in non-epithelial tissues, including the heart and skeletal muscles ${ }^{14)}$. hBD- 4 has been only detected at the mRNA level in keratinocytes, and its synthetic form has been functionally characterized; however, the demonstration of the presence of a native hBD-4 protein in the skin has failed to date ${ }^{15)}$.

hBDs exhibit a broad spectrum of antimicrobial activity against multiple pathogenic microorganisms, including both Gram-positive and -negative bacteria, fungi and viruses. The antimicrobial 
activity of $h B D-1,-2$ and -4 is salt-sensitive, whereas hBD-3 demonstrates a strong antimicrobial effect against many microbes at physiologic salt concentrations ${ }^{16)}$. Furthermore, the antimicrobial activity of $\mathrm{hBD}-3$ is more potent than that of other hBDs, probably because of its amphipathic dimer structure and the fact that hBD-3 is highly positively charged, with a net charge of +11 as opposed to +4 to +7 for the other hBDs ${ }^{17)}$. It is believed that the killing mechanism of AMPs/HDPs is mainly by binding and disrupting negatively charged microbial membranes resulting in the membrane permeabilization, although some AMPs/HDPs might act through different mechanisms of action ${ }^{18)}$.

In addition to their antimicrobial properties, hBDs perform various immune system modulating activities. For example, hBDs act as chemotactic agents for mast cells, neutrophils, $\mathrm{T}$ cells, dendritic cells, monocytes, macrophages and keratinocytes $^{1{ }^{1)}}{ }^{2}$. Furthermore, hBD-2 to -4 induce mast cell degranulation and the production of eicosanoid metabolites such as prostaglandins (PGs) and leukotrienes and regulate skin vascular permeability via mast cell activation ${ }^{19)-21)}$. hBDs also regulate the production of pro-and anti-inflammatory cytokines and chemokines, including those involved in the pathology of various skin diseases ${ }^{22)-25)}$. hBDs also enhance cell proliferation and differentiation and promote angiogenesis and accelerate the wound healing process ${ }^{1{ }^{2}}{ }^{2}$. Furthermore, hBD-2 and $\mathrm{hBD}-3$ are able to bind to and neutralize LPS $^{26)}{ }^{27)}$, and hBD-3 also inhibits neutrophil apoptosis ${ }^{28)}$. Moreover, our group recently demonstrated that $\mathrm{hBD}-3$, but not other hBDs, is crucial for the improvement of tight junction barrier function in human keratinocyte layers ${ }^{29}$. Similar to other AMPs/HDPs, hBDs exhibit their immunomodulatory roles through several molecular mechanisms. These peptides bind to specific pertussis toxin-sensitive G protein-coupled receptors (GPCRs) such as the CC chemokine receptor 2 (CCR2), CCR6, Mas-related G-protein coupled receptor X2 (MrgX2), and other GPCRs which have yet to be identified ${ }^{24}{ }^{24)}{ }^{29)}$. . hBDs also utilize Toll-like receptor (TLR) 1 and TLR2 to stimulate a variety of immune cells ${ }^{33)}$, and transactivate the membrane-bound epidermal growth factor receptor (EGFR) to promote keratinocyte migration and proliferation ${ }^{22)}$.

\section{Human cathelicidin LL-37}

Cathelicidins form a large family of AMPs/HDPs characterized by an $\mathrm{N}$-terminal pro-sequence and a C-terminal antimicrobial peptide domain ${ }^{34)}$. The members of the family mostly form an $\alpha$-helical structure. In humans, LL-37 is the sole member of the cathelicidin family, and its name comes from a 37-amino acid residue peptide starting with a pair of leucines ${ }^{35)}$. LL-37 is generated from hCAP18 (human cationic antibacterial protein of $18 \mathrm{kDa}$ ) following enzymatic cleavage by proteinase 3 and serine proteases of the kallikrein family ${ }^{36-38)}$. LL-37 was initially detected as a constitutive product of neutrophil granules; however, this peptide is also produced by other cell types, including keratinocytes, epithelial cells of the airways and intestine, mast cells, macrophages, $T$ cells, natural killer cells and monocytes ${ }^{1)}$. . The regulation of LL-37 expression is controlled by cytokines, growth factors, bacteria, viruses, injury and vitamin $\mathrm{D}^{1) 2}$. In healthy skin, the expression of LL-37 is barely detected, but it strongly increases following infection or skin injury ${ }^{39}$.

Similar to hBDs, LL-37 also exhibits a broad spectrum of antimicrobial activity against Grampositive and Gram-negative bacteria, fungi and viruses. Furthermore, a number of studies have shown that LL-37 is able to act additively or synergistically with other AMPs/HDPs such as hBDs and lysozyme to kill pathogenic micro$\operatorname{organisms}^{1) 2}$. Experimental studies utilizing a murine ortholog of human LL-37, mCRAMP (murine cathelin-related antimicrobial peptide) have demonstrated the in vivo importance of LL-37 in various infections. For example, mice deficient in CRAMP exhibit increased bacterial colonization and invasion in the skin and intestine ${ }^{40)}$. Furthermore, CRAMP knock-out mice are more susceptible to meningococcal infection and Escherichia coli (E. coli) infection in the urinary tract ${ }^{41)}{ }^{42}$. The antimicrobial activity of LL-37 is variable according to the species and strains of microorganisms; it is salt-sensitive against Gram-positive bacteria but salt-insensitive against Gram-negative bacteria ${ }^{1{ }^{12}}{ }^{2}$.

In addition to its antimicrobial properties, LL-37 could also modify the host immune responses. First, LL-37 has both pro-inflammatory and anti-inflammatory activities that might be modulated by the disease background. LL-37-mediated pro-inflammatory 
responses include the downregulation of $\mathrm{IL}-10$, upregulation of IL-1 13 , IL-12p 40 , IL-18, and cooperation with $\mathrm{IL}-1 \beta$ to enhance the induction of inflammatory mediators ${ }^{43}$. LL-37 also induces mast cell degranulation, the production of lipid mediators and pruritogenic factors, and increases vascular permeability ${ }^{19)}{ }^{20)}{ }^{44}$. LL-37-mediated anti-inflammatory responses include the inhibition of IFN $-\gamma, \mathrm{TNF}-\alpha$, $\mathrm{IL}-4$ and $\mathrm{IL}-12$ production ${ }^{43}$. Second, LL-37 is a chemoattractant for many cell types, including keratinocytes, mast cells, neutrophils, T cells, monocytes and eosinophils ${ }^{1)}{ }^{\text {2) }}{ }^{43}$. Third, LL-37 regulates cell death through the inhibition of apoptosis in neutrophils, keratinocytes, airway and intestinal epithelial cells ${ }^{43}{ }^{45}$ ). LL-37 regulates the production of reactive oxygen species and enhances the release of $\alpha$-defensins by neutrophils ${ }^{46)}$. Fourth, LL-37 enhances cell proliferation and differentiation, exhibits angiogenic and wound healing activities through promoting neovascularization and re-epithelialization, maintains skin homeostasis and strengthens the skin's barrier function ${ }^{1)}{ }^{21}$. . Finally, like hBDs, LL-37 mediates its immunomodulatory functions via the activation of various cell-surface receptors, such as the fMLP receptor FPLR-1, the ATP-gated purinergic receptor $\mathrm{P}_{2} \mathrm{X}_{7}$, EGFR, TLR4 and MrgX2, and intracellular $\mathrm{GAPDH}^{13}{ }^{2)}{ }^{48}{ }^{49}$. Furthermore, still-uncharacterized GPCRs have also been suggested to be responsible for LL-37-mediated mast cell chemotaxis ${ }^{50}$.

\section{S100 proteins}

S100 proteins constitute an extensive family of AMPs/HDPs characterized by the presence of two calcium-binding EF-hand motifs. Twenty-one types of S100 proteins have been identified, and the majority of these proteins (13 members) are located in the epidermal differentiation complex region, which also encodes various members of epidermal differentiation markers ${ }^{51}$. These proteins expressed in the epidermis have been involved in the pathology of various skin diseases ${ }^{52)}$. S100 proteins regulate cell metabolism, proliferation, differentiation, intercellular adhesion, invasion and metastasis $^{53) 54}$. Among S100 proteins, S100A7 (psoriasin), S100A8 (calgranulin A), S100A9 (calgranulin B), S100A12 (calgranulin C), and S100A15 (koebnerisin) exhibit antimicrobial activity ${ }^{1)}$. S100A7 has been well studied and owes its name to the fact that it is detected in high quantity in psoriatic skin lesions compared with normal skin ${ }^{55)}$. S100A7 (psoriasin) is believed to be the principal AMP/HDP constitutively expressed in normal skin ${ }^{56)}$, although its expression is also inducible by Th1-, Th17- and Th22-cytokines, EGF, IGF-1, vitamin D, calcium, sodium butyrate, bacteria and microbial products ${ }^{57)-60}$.

Both S100A7 and S100A15 efficiently kill E. coli but only have weak antimicrobial activity toward Gram-positive bacteria and other microorganisms, whereas the S100A8/S100A9 complex and S100A12 have antimicrobial activities against viruses and fungi ${ }^{1)}$. The abundance of E. coli-cidal S100A7 on human skin suggests a key protective role of this protein against $E$. coli colonization and infection. This finding has been confirmed by experiments on skin from healthy people that demonstrated that S100A7 is a major AMP/HDP that kills E. coli ${ }^{58) 61)}$. It has been hypothesized that the killing mechanism of S100A7 is mainly mediated by zinc deprivation, because zinc is an essential element for bacterial metabolism ${ }^{58)}$. In addition to having antimicrobial activity, S100A7 and S100A15 are chemoattractant for $\mathrm{T}$ cells, monocytes and neutrophils, therefore linking innate and adaptive immunity ${ }^{62)}{ }^{63)}$. S100A7 also enhances the production of reactive oxygen species, increases the cytokine/chemokine production from neutrophils and keratinocytes, and promotes angiogenesis by the induction of endothelial cell proliferation ${ }^{57)}{ }^{63)}{ }^{64)}$. Furthermore, our recent work demonstrated that S100A7 improves skin tight junction barriers in association with keratinocyte differentiation ${ }^{65}$. The major sources of S100A7 and S100A15 are keratinocytes and neutrophils, whereas S100A8 and S100A9 are mainly produced by neutrophils, monocytes and macrophages, although the expression of these proteins might also be induced in keratinocytes and endothelial cells ${ }^{66}$. S100A8 and S100A9 also exhibit chemotactic and angiogenic activities ${ }^{67)}$. S100A7, S100A8, S100A9 and S100A12 act through the multiligand receptor for advanced glycated end products (RAGE), whereas S100A15 acts through a pertussis toxin-sensitive $\mathrm{GPCR}^{64)}$.

\section{Other AMPs/HDPs}

In addition to hBDs, LL-37 and S100 proteins, the skin produces many other AMPs/HDPs such as 
RNases, dermcidin, lysozyme, elafin, secretory leukocyte protease inhibitor (SLPI), adrenomedullin, lactoferrin and catestatin. Among 8 members of RNase family, RNase 1, 4, 5 and 7 are expressed in keratinocytes, with the latter being the highest expressed. RNase 7 was originally isolated from extracts of the stratum corneum where its expression is even higher than that of hBDs, LL-37 and S100A ${ }^{56)}{ }^{68)}$. In addition to their antimicrobial and ribonucleolytic activities, RNase family members have neurotoxic, angiogenic and immunomodulatory activities ${ }^{69)}$. Dermcidin peptides are primarily constitutively found in the eccrine sweat glands within the dermis of the human skin and secreted into the sweat ${ }^{70)}$ They exhibit antimicrobial activity, stimulate keratinocytes to produce cytokines and chemokines ${ }^{71)}$, and enhance cell growth and the survival of breast cancer cells ${ }^{72)}$. Lysozyme protects against bacteria and viruses, and we have shown that this effect is synergistic with other AMPs/HDPs such as hBDs and LL-37 ${ }^{73)-75)}$. It also enhances phagocytosis and cell proliferation and controls inflammation ${ }^{1)}{ }^{2)}$. Elafin and SLPI are members of the antileukoproteinase superfamily of proteinase inhibitors and protect tissues from protease damage during inflammation ${ }^{1)}{ }^{2)}$. Both elafin and SLPI possess antimicrobial, chemotactic and wound healing activities, and are involved in inflammation regulation ${ }^{12)}{ }^{76}$. Finally, catestatin and its variants are antimicrobials, enhance cytokine/chemokine production in mast cells and keratinocytes and are promoters of cell proliferation, wound healing and angiogenesis in endothelial cells and keratinocytes ${ }^{77)-80}$.

\section{The role of important AMPs in human skin diseases}

\section{AMPs/HDPs in psoriasis}

Psoriasis is an inflammatory non-infectious skin disorder with an estimated world-wide prevalence of $3 \%$; the disorder causes significant morbidity and affects the quality of life in many patients ${ }^{81}$. The foremost clinical features of psoriasis include a typical hyper-proliferation and abnormal differentiation of keratinocytes, which is associated with the excessive production of pro-inflammatory cytokines/chemokines and activated $\mathrm{T}$ cells and plasmacytoid dendritic cells $(\mathrm{pDCs})^{82}$. The psoriatic skin produces almost all well-known AMPs/HDPs, including hBD-1, hBD-2, hBD-3, LL-37, S100A7, S100A8, S100A9, S100A15, RNase 7, lysozyme, elafin and SLPI ${ }^{1)}$. . hBD-2 and hBD-3 were first identified in psoriatic scales ${ }^{14)}{ }^{83}$, and S100A7 was named psoriasin due to its abundance in psoriatic skin ${ }^{58)}$. The excessive production of AMPs/HDPs in psoriatic skin has been suggested to be a major explanation of the unexpected observation that patients with psoriasis experience fewer bacterial and viral infections compared with AD patients ${ }^{84)}$. The mechanism of AMP/HDP overexpression in psoriatic skin is not well understood; however, it appears that an abundance of Th1- and Th17derived inflammatory cytokines in psoriasis is a major cause of this induction ${ }^{85)}{ }^{86)}$.

In addition to protecting against pathogenic microorganisms in psoriasis, AMPs/HDPs initiate anti-inflammatory functions in psoriatic keratinocytes. We recently reported that $\mathrm{hBD}-3$ primes keratinocytes to express an anti-inflammatory cytokine IL-37, which is a novel target for the pathogenesis and therapy of psoriasis ${ }^{24)}$. Intracellular or cytosolic LL-37 has been shown to block activation of DNA-induced formation of inflammasomes in keratinocytes, resulting to the inhibition of IL-1 $\beta$ release ${ }^{87788}$. Furthermore, the overexpression of S100A8 and S100A9 leads to induction of keratinocyte differentiation and inhibition of keratinocyte proliferation and survival, key features of psoriasis ${ }^{89)}{ }^{90}$. These observations suggest that AMPs/HDPs might contribute to the suppression of psoriatic skin inflammatory and innate immune responses.

The presence of AMPs/HDPs in psoriasis might also contribute to its pathogenesis. First, LL-37 inhibits keratinocyte apoptosis ${ }^{91)}$, and similar to hBDs and S100A8/S100A9, LL-37 induces keratinocyte proliferation and migration ${ }^{22)}{ }^{67)}$. Second, LL-37, hBD-2 and hBD-3 activate pDCs through the formation of aggregates with self-DNA, resulting in production of IFN- $\alpha, \mathrm{TNF}^{-} \alpha$ and IL-6, therefore initiating auto-inflammatory responses in psoriasis ${ }^{92-94)}$. Third, hBDs, LL-37 and S100A proteins trigger recruitment of immune cells such as $\mathrm{T}$ cells, DCs, neutrophils, monocytes/macrophages, which play a key role in the pathogenesis of psoriasis ${ }^{1)}{ }^{26}$ ). Fourth, AMPs/HDPs prime keratinocytes for enhanced secretion of various proinflammatory cytokines and chemokines that play 
important roles in the development of psoriatic lesions ${ }^{22)}{ }^{23)}$. hBDs and LL-37 also cause mast cell degranulation and the production of lipid mediators and pruritogenic factors, which might contribute to pruritus in psoriasis ${ }^{19)-21)}$. Fifth, hBDs, LL-37 and S100A7 induce the proliferation and migration of endothelial cells and promote angiogenesis and neovascularization in psoriatic lesions ${ }^{1)}{ }^{2)}$ ).

\section{AMPs/HDPs in AD}

$\mathrm{AD}$, also known as atopic eczema, is one of the most common chronic and relapsing inflammatory skin diseases and is frequently associated with recurrent bacterial (particularly S. aureus) and viral infections ${ }^{96)}{ }^{97}$. $\mathrm{AD}$ pathogenesis, which is complex and still not fully understood, involves both genetic and environmental components, together with immune dysregulation and epidermal barrier disruption ${ }^{98}$. The defect in innate immune response in $\mathrm{AD}$ was proposed by Ong et al. in 2002 when a deficiency in the expression of hBD-2 and LL-37 was observed in lesional AD skin in contrast to the increased expression in psoriatic skin ${ }^{84}$, and this finding was further confirmed by de Jongh $e t a l^{99)}$. Furthermore, patients with eczema herpeticum, one of the uncommon complications of $\mathrm{AD}$, have pronounced defects in the expression of $\mathrm{hBD}-2$, hBD-3 and LL-37 in their lesional skin compared with patients with $\mathrm{AD}$ or psoriasis ${ }^{100}$. AD skin has increased production of the Th2-derived cytokines IL-4, IL-10 and IL-13 and reduced production of IL-1 $\beta$, IL-22, IFN $-\gamma$ and TNF- $\alpha$, which are crucial for the induction of AMPs/HDPs ${ }^{84)}{ }^{101)}{ }^{102}$. The down-regulation of inducible AMPs/HDPs in AD has been attributed to the inhibitory effects of overexpressed Th2 cytokines on these peptides ${ }^{101)}$. This finding is also supported by the observation that neutralization of Th2 cytokines resulted into elevated expression of $\mathrm{hBD}-2, \mathrm{hBD}-3$ and LL-37 in $\mathrm{AD}$ skin ${ }^{103)}$. In contrast, Kisich et al. reported that the mobilization of $\mathrm{hBD}-3$ on $S$. aureus is impaired in $\mathrm{AD}$ patients compared with healthy subjects because of excess amounts of Th2 cytokines that interfere with antimicrobial activity ${ }^{104)}$. Therefore, it could be assumed that controlling the overproduction of Th2 cytokines in AD skin might lead to recovery of inducible AMPs/HDPs, reducing the frequent bacterial and viral infections seen in $\mathrm{AD}$ patients. A recent report found that pimecrolimus, a drug used in the treatment of $\mathrm{AD}$, induces S100A8 and S100A9 expression, which is undetectable in $\mathrm{AD}$ skin ${ }^{105)}$.

It is important to note that $\mathrm{AD}$ is not associated with a general deficiency in the production of AMPs/HDPs. Enhanced expression of $\mathrm{hBD}^{-2}$, hBD-3, S100A7 and RNase 7 was demonstrated in lesional skin compared with non-lesional skin ${ }^{59)}{ }^{106)}{ }^{107)}$. It is believed that increased expression of AMPs/HDPs in AD lesional skin is a result of the disturbed skin barrier, because expression of hBD-3, S100A7 and RNase 7 was upregulated by experimental barrier disruption caused by tape stripping ${ }^{59)}{ }^{106)}$. However, although LL-37 expression is rapidly increased in healthy skin following wounding, this expression is suppressed in wounded $\mathrm{AD}$ lesions, suggesting that not all AMPs/HDPs could be induced by barrier disruption in $\mathrm{AD}$ skin ${ }^{108)}$.

AMPs/HDPs might contribute to the development of $\mathrm{AD}$ pathogenesis. A recent investigation by Kanda et al. showed that hBD-2 and hBD- 3 enable keratinocytes to produce the Th2 cytokines IL-4, IL-13 and IL-31 ${ }^{109)}$. Furthermore, our group has demonstrated that hBD-2, hBD-3, hBD-4 and LL-37 induce mast cell degranulation and the production of $\mathrm{PGD}_{2}, \mathrm{PGE}_{2}$, leukotriene $\mathrm{C}_{4}$ and IL-31 ${ }^{19-211}$. These observations imply that AMPs/ HDPs might aggravate allergic reactions such as pruritus in $\mathrm{AD}$ skin. However, contrastingly, we recently showed that LL-37 induces upregulation of an epidermal nerve repulsion factor, semaphorin $3 \mathrm{~A}$ by human keratinocytes ${ }^{110)}$. Because the levels of both LL-37 and semaphorin $3 \mathrm{~A}$ are reduced in $\mathrm{AD}$ patients, recovery of this peptide in $\mathrm{AD}$ patients might be useful to suppress itch. Moreover, LL-37 suppresses double-stranded RNA-induced thymic stromal lymphopoietin, suggesting that LL-37 might contribute to the suppression of Th2-driven AD skin inflammation induced by viral or selfdouble-stranded $\mathrm{RNA}^{111}$. Taken together, the complete picture of the roles of AMPs/HDPs in AD remains to be further elucidated.

\section{AMPs/HDPs in rosacea}

Rosacea is another common chronic inflammatory skin disease characterized by persistent facial erythema, telangiectasias, edema, inflammatory papules and pustules that primarily affect the nose, 
cheeks, central forehead and chin ${ }^{112)}{ }^{113)}$. Until now, the complete pathophysiology of rosacea has been uncertain. It was proposed that rosacea is associated with abnormal skin vasculature and inflammation, but recently, it was shown that factors that trigger innate immune responses such as aberrant release of LL-37 and its derived peptides by keratinocytes could aggravate the clinical symptoms of rosacea. Abnormally high expression and processing of LL-37 has been found in rosacea patients ${ }^{114)}{ }^{115)}$. In lesional skin of rosacea, increased activity of a serine protease of the kallikrein family, kallikrein 5, leads to LL-37 activation and processing into smaller fragments that are not found in normal skin ${ }^{115)}{ }^{116)}$. These abnormal LL-37 fragments control leukocyte recruitment, angiogenesis, the expression of extracellular matrix components and production of vasoactive and pro-inflammatory cytokine IL-8 ${ }^{95}$ 117) 118). An injection of these proteolytic fragments into mice results in the typical clinical presentations of rosacea, which include erythema, vascular dilatation, flushing and telangiectasias ${ }^{115)}{ }^{119)}$. These findings suggest that high levels of kallikrein 5 along with very high concentrations of LL-37 and abnormally processed LL-37 isoforms play a crucial role in the chronic inflammation patients with rosacea. Although the mechanism by which LL-37 expression is elevated in rosacea has not been fully elucidated, the vitamin D- and TLR2-pathways are likely involved. Vitamin $\mathrm{D}$ is a stronger inducer of LL-37, and genetic polymorphisms of the vitamin $\mathrm{D}$ receptor have been associated with some types of rosacea ${ }^{120}$. This association suggests that the vitamin plays a role in the development of rosacea. Because exposure to UVB causes activation of vitamin D and subsequent augmentation of LL-37 expression in keratinocytes ${ }^{121)}{ }^{122}$, this finding might explain the frequency of rosacea in the face. Avoiding exposure to sun light might be recommended in rosacea patients.

\section{AMPs/HDPs in acne vulgaris}

Acne vulgaris is a chronic inflammatory disorder of the pilosebaceous unit (hair follicle, hair shaft and sebaceous gland), which often occurs on the face, chest and back of adolescents and young adults. The pathogenesis of acne involves several factors including inflammation, abnormal keratinization, excess sebum production and colonization with
Propionibacterium acnes (P.acnes) ${ }^{123)}$. P. acnes contributes to acne inflammation through the release of extracellular enzymes, recruitment of neutrophils, and activation of monocytes to release pro-inflammatory cytokines ${ }^{124}$. Upregulation of AMPs/HDPs such as hBD-1, hBD-2 and hBD-4, was observed in lesional skin biopsies from acne patients compared with controls ${ }^{125)-127)}$. This finding suggests that these peptides might play a role in acne vulgaris. Furthermore, cathelicidin LL-37 and S100A7 are expressed in keratinocytes and sebocytes and act synergistically to inhibit the colonization of $P$. acnes. Taken together, given that numerous AMPs/HDPs possess killing ability against $P$. acnes, neutralize pro-inflammatory bacterial factors and directly inhibit the production of inflammatory cytokines from host cells ${ }^{1{ }^{2}}$, these peptides are potential candidates for the prevention and treatment of acne vulgaris.

\section{AMPs/HDPs in other skin disorders}

In addition to the above-mentioned skin diseases, AMPs/HDPs also play roles in the pathogenesis in a myriad of skin conditions. For example, burns are generally associated with decreased levels of AMPs/HDPs, which might explain the increased susceptibility to bacterial infection and sepsis in burned patients ${ }^{128)}{ }^{129}$ ). In contrast, the expression of hBDs, LL-37, S100A7 and RNase 7 is enhanced after skin injury. These peptides promote angiogenesis, vascularization, wound re-epithelialization and wound healing ${ }^{1)}{ }^{2)}$, suggesting that AMPs/HDPs are promising agents for therapeutic development for wound healing. hBDs have been reported to be increased in folliculitis, scleroderma and lichen planus ${ }^{130)-132}$; however, their precise functions in these diseases remain to be further clarified. LL-37 has been found to be strongly expressed in hidradenitis suppurativa, systemic lupus erythematosus and contact dermatitis to nickel, verruca vulgaris and condyloma acuminata ${ }^{1)}{ }^{2}$. In addition to psoriasis and $\mathrm{AD}, \mathrm{S} 100 \mathrm{~A} 7$ is also over-expressed in many other epidermal inflammatory diseases, including mycosis fungoides, Darier's disease, and inflammatory lichen sclerosus et atrophicus, and squamous cell carcinoma of the skin ${ }^{1)}{ }^{2}$. AMPs/ HDPs are implicated in many skin diseases; however, their precise functions in these disorders have yet to be clarified. 
Table-1 Selected AMPs/HDPs in clinical trials for skin diseases ${ }^{132)-134 \text { ) }}$

\begin{tabular}{|c|c|c|c|c|}
\hline Name & Parent peptide/source & Company & Application & Clinical trial stage \\
\hline LL-37 & Human cathelicidin & Pergamum & Venous leg ulcers & Phase II \\
\hline Brilacidin/ PMX-30063 & Defensin mimetic & PolyMedix & $\begin{array}{l}\text { Acute bacterial skin } \\
\text { and skin structure } \\
\text { infections }\end{array}$ & Phase II \\
\hline DPK-060 & Derivative of kininogen & Pergamum & $\begin{array}{l}\text { Skin infections in } \\
\text { atopic dermatitis }\end{array}$ & Phase II \\
\hline LTX-109 & Lactoferrin B & Lytix Biopharma & $\begin{array}{l}\text { Gram-positive bacterial } \\
\text { skin infections. } \\
\text { Diabetic foot infections }\end{array}$ & Phase IIa \\
\hline GSK1322322 & Actinonin & GlaxoSmithKline & $\begin{array}{l}\text { Acute bacterial skin } \\
\text { infections }\end{array}$ & Phase II \\
\hline HB1345 & Synthetic lipohexapeptide & Helix BioMedix & Acne & Pre-clinical phase \\
\hline Pexiganan acetate & Magainin & $\begin{array}{c}\text { Dipexium } \\
\text { Pharmaceuticals }\end{array}$ & Diabetic foot ulcers & Phase III \\
\hline XOMA 629 & Derivative of BPI & Xoma & Impetigo & Phase IIa \\
\hline Omiganan (MBI-226) & Indolicidin & $\begin{array}{l}\text { Migenix/BioWest } \\
\text { Therapeutics }\end{array}$ & Prevention of acne & Phase III \\
\hline Omiganan (CLS001) & Indolicidin & $\begin{array}{c}\text { Cutanea Life } \\
\text { Sciences/Migenix }\end{array}$ & Severe acne and rosacea & Phase II/III \\
\hline
\end{tabular}

BPI: Bactericidal permeability-increasing protein

\section{Conclusions and outlook}

In addition to the prevention of pathogen invasion, AMPs/HDPs are strong regulators of the cutaneous immune system. Despite notable findings reported on the multiple functions of these proteins/peptides in normal human skin and numerous infectious and/or inflammatory skin diseases, much more work needs to be done to understand their cellular/molecular mechanisms. Mastering the biological functions and the underlying mechanisms of AMPs/HDPs would improve our understanding in the pathophysiology of skin disorders and enable us to develop novel therapeutic targets or improve established treatments for several dermatological conditions. A summary of selected AMPs/HDPs or their derivatives in drug development for various skin diseases is shown in Table-1. Further research should focus on how to reduce the cytotoxicity of AMPs/HDPs and at the same time improve their antimicrobial and immunomodulatory activities. This improvement could lead to innovative treatments for many skin diseases through the effects of AMPs/HDPs.

\section{Acknowledgments}

Parts of the work presented herein were sup- ported by a Grant-in-Aid for Scientific Research from the Ministry of Education, Culture, Sports, Science and Technology, Japan (Grant number: 26461703 to F. N.) and by the Atopy (Allergy) Research Center, Juntendo University, Tokyo, Japan.

We express our deepest gratitude to all members of the Atopy (Allergy) Research Center, Juntendo University Graduate School of Medicine for their comments and to Michiyo Matsumoto for secretarial assistance.

\section{References}

1) Niyonsaba F, Nagaoka I, Ogawa H, Okumura K: Multifunctional antimicrobial proteins and peptides: Natural activators of immune systems. Curr Pharm Des, 2009; 15: 2393-2413.

2) Niyonsaba F, Nagaoka I, Ogawa H: Human defensins and cathelicidins in the skin: Beyond direct antimicrobial properties. Crit Rev Immunol, 2006; 26: 545-576.

3) Hancock REW, Sahl HG: Antimicrobial and hostdefense peptides as new anti-infective therapeutic strategies. Nat Biotechnol, 2006; 24: 1551-1557.

4) Oppenheim JJ, Yang D: Alarmins: Chemotactic activators of immune responses. Curr Opin Immunol, 2005; 17: 359-365.

5) Selsted ME, Tang YQ, Morris WL, et al: Purification, primary structures, and antibacterial activities of betadefensins, a new family of antimicrobial peptides from bovine neutrophils. J Biol Chem, 1993; 268: 6641-6648.

6) Tang YQ, Yuan J, Osapay G, et al: A cyclic antimicrobial peptide produced in primate leukocytes by the 
ligation of two truncated alpha-defensins. Science, 1999; 286: 498-502.

7) Ganz T, Selsted ME, Szklarek D, et al: Defensins. Natural peptide antibiotics of human neutrophils. J Clin Invest, 1985; 76: 1427-1435.

8) Salzman NH, Ghosh D, Huttner KM, Paterson Y, Bevins $\mathrm{CL}$ : Protection against enteric salmonellosis in transgenic mice expressing a human intestinal defensin. Nature, 2003; 422: 522-526.

9) Selsted ME, Ouellette AJ: Mammalian defensins in the antimicrobial immune response. Nat Immunol, 2005; 6: 551-557.

10) Nguyen TX, Cole AM, Lehrer RI: Evolution of primate theta-defensins: A serpentine path to a sweet tooth. Peptides, 2003; 24: 1647-1654.

11) Sorensen OE, Thapa DR, Rosenthal A, Liu L, Roberts AA, Ganz T: Differential regulation of beta-defensin expression in human skin by microbial stimuli. J Immunol, 2005; 174: 4870-4879.

12) Huh WK, Oono T, Shirafuji Y, et al: Dynamic alteration of human beta-defensin 2 localization from cytoplasm to intercellular space in psoriatic skin. J Mol Med (Berl), 2002; 80: 678-684.

13) Oren A, Ganz T, Liu L, Meerloo T: In human epidermis, beta-defensin 2 is packaged in lamellar bodies. Exp Mol Pathol, 2003; 74: 180-182.

14) Harder J, Bartels J, Christophers E, Schroder JM: Isolation and characterization of human beta-defen$\sin -3$, a novel human inducible peptide antibiotic. J Biol Chem, 2001; 276: 5707-5713.

15) Garcia JR, Krause A, Schulz S, et al: Human betadefensin 4: A novel inducible peptide with a specific salt-sensitive spectrum of antimicrobial activity. FASEB J, 2001; 15: 1819-1821.

16) Garcia JR, Jaumann F, Schulz S, et al: Identification of a novel, multifunctional beta-defensin (human betadefensin 3) with specific antimicrobial activity. Its interaction with plasma membranes of xenopus oocytes and the induction of macrophage chemoattraction. Cell Tissue Res, 2001; 306: 257-264.

17) Schibli DJ, Hunter HN, Aseyev V, et al: The solution structures of the human beta-defensins lead to a better understanding of the potent bactericidal activity of hBD-3 against Staphylococcus aureus. J Biol Chem, 2002; 277: 8279-8289.

18) Hancock RE, Rozek A: Role of membranes in the activities of antimicrobial cationic peptides. FEMS Microbiol Lett, 2002; 206: 143-149.

19) Niyonsaba F, Someya A, Hirata M, Ogawa H, Nagaoka I: Evaluation of the effects of peptide antibiotics human beta-defensins $-1 /-2$ and LL-37 on histamine release and prostaglandin $\mathrm{D}_{2}$ production from mast cells. Eur J Immunol, 2001; 31: 1066-1075.

20) Niyonsaba F, Ushio H, Hara M, et al: Antimicrobial peptides human beta-defensins and cathelicidin LL-37 induce the secretion of a pruritogenic cytokine IL-31 by human mast cells. J Immunol, 2010; 184: 3526-3534.

21) Chen $X$, Niyonsaba F, Ushio $H$, et al: Antimicrobial peptides human beta-defensin (hBD) -3 and hBD-4 activate mast cells and increase skin vascular permeability. Eur J Immunol, 2007; 37: 434-444.

22) Niyonsaba F, Ushio H, Nakano N, et al: Antimicrobial peptides human beta-defensins stimulate epidermal keratinocyte migration, proliferation and production of pro-inflammatory cytokines and chemokines. J Invest
Dermatol, 2007; 127: 594-604.

23) Niyonsaba F, Ushio H, Nagaoka I, Okumura K, Ogawa $\mathrm{H}$ : The human beta-defensins $(-1,-2,-3,-4)$ and cathelicidin LL-37 induce IL-18 secretion through p38 and ERK MAPK activation in primary human keratinocytes. J Immunol, 2005; 175: 1776-1784.

24) Smithrithee R, Niyonsaba F, Kiatsurayanon C, et al: Human beta-defensin-3 increases the expression of interleukin-37 through CCR6 in human keratinocytes. J Dermatol Sci, 2015; 77: 46-53.

25) Nguyen TT, Niyonsaba F, Ushio $H$, et al: Interleukin-36 cytokines enhance the production of host defense peptides psoriasin and LL-37 by human keratinocytes through activation of MAPKs and NF-kappaB. J Dermatol Sci, 2012; 68: 63-66.

26) Kim C, Slavinskaya Z, Merrill AR, Kaufmann SH: Human alpha-defensins neutralize toxins of the monoADP-ribosyltransferase family. Biochem J, 2006; 399: 225-229.

27) Scott MG, Hancock RE: Cationic antimicrobial peptides and their multifunctional role in the immune system. Crit Rev Immunol, 2000; 20: 407-431.

28) Nagaoka I, Niyonsaba F, Tsutsumi-Ishii Y, Tamura H, Hirata M: Evaluation of the effect of human betadefensins on neutrophil apoptosis. Int Immunol, 2008; 20: $543-553$

29) Kiatsurayanon C, Niyonsaba F, Smithrithee R, et al: Host defense (antimicrobial) peptide, human betadefensin-3, improves the function of the epithelial tight-junction barrier in human keratinocytes. J Invest Dermatol, 2014; 134: 2163-2173.

30) Niyonsaba F, Iwabuchi K, Matsuda H, Ogawa H, Nagaoka I: Epithelial cell-derived human beta-defensin-2 acts as a chemotaxin for mast cells through a pertussis toxin-sensitive and phospholipase C-dependent pathway. Int Immunol, 2002; 14: 421-426.

31) Subramanian H, Gupta K, Lee D, Bayir AK, Ahn H, Ali $\mathrm{H}$ : Beta-defensins activate human mast cells via Mas-related gene X2. J Immunol, 2013; 191: 345-352.

32) Rohrl J, Yang D, Oppenheim JJ, Hehlgans T: Human beta-defensin 2 and 3 and their mouse orthologs induce chemotaxis through interaction with CCR2. J Immunol, 2010; 184: 6688-6694.

33) Funderburg N, Lederman MM, Feng $Z$, et al: Human beta-defensin-3 activates professional antigen-presenting cells via Toll-like receptors 1 and 2. Proc Natl Acad Sci U S A, 2007; 104: 18631-18635.

34) Zanetti M, Gennaro R, Romeo D: Cathelicidins: A novel protein family with a common proregion and a variable C-terminal antimicrobial domain. FEBS Lett, 1995; 374: $1-5$

35) Larrick JW, Morgan JG, Palings I, Hirata M, Yen MH: Complementary DNA sequence of rabbit CAP18--a unique lipopolysaccharide binding protein. Biochem Biophys Res Commun, 1991; 179: 170-175.

36) Sorensen OE, Follin P, Johnsen AH, et al: Human cathelicidin, hCAP-18, is processed to the antimicrobial peptide LL-37 by extracellular cleavage with proteinase 3. Blood, 2001; 97: 3951-3959.

37) Sorensen OE, Gram L, Johnsen AH, et al: Processing of seminal plasma hCAP-18 to ALL-38 by gastricsin: A novel mechanism of generating antimicrobial peptides in vagina. J Biol Chem, 2003; 278: 28540-28546.

38) Murakami M, Lopez-Garcia B, Braff M, Dorschner RA, Gallo RL: Postsecretory processing generates multiple 
cathelicidins for enhanced topical antimicrobial defense. J Immunol, 2004; 172: 3070-3077.

39) Frohm M, Gunne H, Bergman AC, et al: Biochemical and antibacterial analysis of human wound and blister fluid. Eur J Biochem, 1996; 237: 86-92.

40) Howell MD, Jones JF, Kisich KO, Streib JE, Gallo RL, Leung DY: Selective killing of vaccinia virus by LL-37: Implications for eczema vaccinatum. J Immunol, 2004; 172: 1763-1767.

41) Bergman P, Johansson L, Wan H, et al: Induction of the antimicrobial peptide CRAMP in the blood-brain barrier and meninges after meningococcal infection. Infect Immun, 2006; 74: 6982-6991.

42) Chromek M, Slamova Z, Bergman $P$, et al: The antimicrobial peptide cathelicidin protects the urinary tract against invasive bacterial infection. Nat Med, 2006; 12: 636-641.

43) Kahlenberg JM, Kaplan MJ: Little peptide, big effects: The role of LL-37 in inflammation and autoimmune disease. J Immunol, 2013; 191: 4895-4901.

44) Chen $X$, Niyonsaba F, Ushio H, et al: Human cathelicidin LL-37 increases vascular permeability in the skin via mast cell activation, and phosphorylates MAP kinases p38 and ERK in mast cells. J Dermatol Sci, 2006; 43: $63-66$.

45) Nagaoka I, Tamura H, Hirata M: An antimicrobial cathelicidin peptide, human CAP18/LL-37, suppresses neutrophil apoptosis via the activation of formyl-peptide receptor-like 1 and $\mathrm{P}_{2} \mathrm{X}_{7}$. J Immunol, 2006; 176: 3044-3052.

46) Zheng Y, Niyonsaba F, Ushio H, et al: Cathelicidin LL-37 induces the generation of reactive oxygen species and release of human alpha-defensins from neutrophils. Br J Dermatol, 2007; 157: 1124-1131.

47) Akiyama T, Niyonsaba F, Kiatsurayanon C, et al: The human cathelicidin LL-37 host defense peptide upregulates tight junction-related proteins and increases human epidermal keratinocyte barrier function. J Innate Immun, 2014; 6: 739-753.

48) Subramanian H, Gupta K, Guo Q, Price R, Ali H: Mas-related gene X2 (MrgX2) is a novel G protein-coupled receptor for the antimicrobial peptide LL-37 in human mast cells: Resistance to receptor phosphorylation, desensitization, and internalization. J Biol Chem, 2011; 286: 44739-44749.

49) Tokumaru S, Sayama K, Shirakata Y, et al: Induction of keratinocyte migration via transactivation of the epidermal growth factor receptor by the antimicrobial peptide LL-37. J Immunol, 2005; 175: 4662-4668.

50) Niyonsaba F, Iwabuchi K, Someya A, et al: A cathelicidin family of human antibacterial peptide LL-37 induces mast cell chemotaxis. Immunology, 2002; 106: $20-26$.

51) Mischke D, Korge BP, Marenholz I, Volz A, Ziegler A: Genes encoding structural proteins of epidermal cornification and S100 calcium-binding proteins form a gene complex ("epidermal differentiation complex") on human chromosome 1q21. J Invest Dermatol, 1996; 106: 989-992.

52) Eckert RL, Broome AM, Ruse M, Robinson N, Ryan D, Lee K: S100 proteins in the epidermis. J Invest Dermatol, 2004; 123: 23-33.

53) Ridinger K, Ilg EC, Niggli FK, Heizmann CW, Schafer BW: Clustered organization of S100 genes in human and mouse. Biochim Biophys Acta, 1998; 1448: 254-
263.

54) Vegfors J, Petersson S, Kovacs A, Polyak K, Enerback C: The expression of psoriasin (S100A7) and CD24 is linked and related to the differentiation of mammary epithelial cells. PLoS One, 2012; 7: e53119.

55) Madsen P, Rasmussen HH, Leffers H, et al: Molecular cloning, occurrence, and expression of a novel partially secreted protein "psoriasin" that is highly up-regulated in psoriatic skin. J Invest Dermatol, 1991; 97: 701-712.

56) Schroder JM, Harder J: Antimicrobial skin peptides and proteins. Cell Mol Life Sci, 2006; 63: 469-486.

57) Niyonsaba F, Hattori F, Maeyama K, Ogawa H, Okamoto K: Induction of a microbicidal protein psoriasin (S100A7), and its stimulatory effects on normal human keratinocytes. J Dermatol Sci, 2008; 52: 216219.

58) Glaser R, Harder J, Lange H, Bartels J, Christophers E, Schroder JM: Antimicrobial psoriasin (S100A7) protects human skin from Escherichia coli infection. Nat Immunol, 2005; 6: 57-64.

59) Glaser R, Meyer-Hoffert U, Harder J, et al: The antimicrobial protein psoriasin (S100A7) is upregulated in atopic dermatitis and after experimental skin barrier disruption. J Invest Dermatol, 2009; 129: 641-649.

60) Abtin A, Eckhart L, Mildner M, Gruber F, Schroder JM, Tschachler E: Flagellin is the principal inducer of the antimicrobial peptide S100A7c (psoriasin) in human epidermal keratinocytes exposed to Escherichia coli. FASEB J, 2008; 22: 2168-2176.

61) Lee KC, Eckert RL: S100A7 (psoriasin) --mechanism of antibacterial action in wounds. J Invest Dermatol, 2007; 127: 945-957.

62) Jinquan T, Vorum H, Larsen CG, et al: Psoriasin: A novel chemotactic protein. J Invest Dermatol, 1996; 107: $5-10$.

63) Zheng Y, Niyonsaba F, Ushio H, et al: Microbicidal protein psoriasin is a multifunctional modulator of neutrophil activation. Immunology, 2008; 124: 357-367.

64) Shubbar E, Vegfors J, Carlstrom M, Petersson S, Enerback C: Psoriasin (S100A7) increases the expression of ROS and VEGF and acts through RAGE to promote endothelial cell proliferation. Breast Cancer Res Treat, 2012; 134: 71-80.

65) Hattori F, Kiatsurayanon C, Okumura K, et al: The antimicrobial protein S100A7/psoriasin enhances expression of keratinocyte differentiation markers and strengthens the skin tight junction barrier. $\mathrm{Br} \mathrm{J}$ Dermatol, 2014; 171: 742-753.

66) Batycka-Baran A, Maj J, Wolf R, Szepietowski JC: The new insight into the role of antimicrobial proteins-alarmins in the immunopathogenesis of psoriasis. J Immunol Res, 2014; 2014: 628289.

67) Lee Y, Jang S, Min JK, Lee K, et al: S100A8 and S100A9 are messengers in the crosstalk between epidermis and dermis modulating a psoriatic milieu in human skin. Biochem Biophys Res Commun, 2012; 423: 647-653.

68) Harder J, Schroder JM: RNase 7, a novel innate immune defense antimicrobial protein of healthy human skin. J Biol Chem, 2002; 277: 46779-46784.

69) Sorrentino S: The eight human “canonical” ribonucleases: Molecular diversity, catalytic properties, and special biological actions of the enzyme proteins. FEBS Lett, 2010; 584: 2194-2200. 
70) Rieg S, Steffen H, Seeber S, et al: Deficiency of dermcidin-derived antimicrobial peptides in sweat of patients with atopic dermatitis correlates with an impaired innate defense of human skin in vivo. J Immunol, 2005; 174: 8003-8010.

71) Niyonsaba F, Suzuki A, Ushio H, Nagaoka I, Ogawa H, Okumura K: The human antimicrobial peptide dermcidin activates normal human keratinocytes. $\mathrm{Br} \mathrm{J}$ Dermatol, 2009; 160: 243-249.

72) Porter D, Weremowicz S, Chin K, et al: A neural survival factor is a candidate oncogene in breast cancer. Proc Natl Acad Sci U S A, 2003; 100: 1093110936.

73) Pellegrini A, Thomas U, Bramaz N, Klauser S, Hunziker $\mathrm{P}$, von Fellenberg R: Identification and isolation of a bactericidal domain in chicken egg white lysozyme. J Appl Microbiol, 1997; 82: 372-378.

74) Ibrahim HR, Matsuzaki T, Aoki T: Genetic evidence that antibacterial activity of lysozyme is independent of its catalytic function. FEBS Lett, 2001; 506: 27-32.

75) Chen X, Niyonsaba F, Ushio H, et al: Synergistic effect of antibacterial agents human beta-defensins, cathelicidin LL-37 and lysozyme against Staphylococcus aureus and Escherichia coli. J Dermatol Sci, 2005; 40: 123-132.

76) Aung G, Niyonsaba F, Ushio H, Ikeda S, Okumura K, Ogawa H: Elafin and secretory leukocyte protease inhibitor stimulate the production of cytokines and chemokines by human keratinocytes via MAPK/ERK and NF-kappaB activation. J Dermatol Sci, 2011; 63: 128-131.

77) Aung G, Niyonsaba F, Ushio H, et al: A neuroendocrine antimicrobial peptide, catestatin, stimulates interleukin-8 production from human keratinocytes via activation of mitogen-activated protein kinases. J Dermatol Sci, 2011; 61: 142-144.

78) Aung G, Niyonsaba F, Ushio H, et al: Catestatin, a neuroendocrine antimicrobial peptide, induces human mast cell migration, degranulation and production of cytokines and chemokines. Immunology, 2011; 132: 527-539.

79) Hoq MI, Niyonsaba F, Ushio H, Aung G, Okumura K, Ogawa H: Human catestatin enhances migration and proliferation of normal human epidermal keratinocytes. J Dermatol Sci, 2011; 64: 108-118.

80) Theurl M, Schgoer W, Albrecht K, et al: The neuropeptide catestatin acts as a novel angiogenic cytokine via a basic fibroblast growth factor-dependent mechanism. Circ Res, 2010; 107: 1326-1335.

81) Nickoloff BJ, Nestle FO: Recent insights into the immunopathogenesis of psoriasis provide new therapeutic opportunities. J Clin Invest, 2004; 113: 16641675.

82) Korting HC, Schollmann C, Stauss-Grabo M, Schafer-Korting M: Antimicrobial peptides and skin: A paradigm of translational medicine. Skin Pharmacol Physiol, 2012; 25: 323-334.

83) Harder J, Bartels J, Christophers E, Schroder JM: A peptide antibiotic from human skin. Nature, 1997; 387: 861.

84) Ong PY, Ohtake T, Brandt C, et al: Endogenous antimicrobial peptides and skin infections in atopic dermatitis. N Engl J Med, 2002; 347: 1151-1160.

85) Nestle FO, Kaplan DH, Barker J: Psoriasis. N Engl J Med, 2009; 361: 496-509.

86) Schittek B, Paulmann M, Senyurek I, Steffen H: The role of antimicrobial peptides in human skin and in skin infectious diseases. Infect Disord Drug Targets, 2008; 8: $135-143$.

87) Morizane S, Yamasaki K, Muhleisen B, et al: Cathelicidin antimicrobial peptide LL-37 in psoriasis enables keratinocyte reactivity against TLR9 ligands. J Invest Dermatol, 2012; 132: 135-143.

88) Dombrowski Y, Peric M, Koglin S, et al: Cytosolic DNA triggers inflammasome activation in keratinocytes in psoriatic lesions. Sci Transl Med, 2011; 3: 82ra38.

89) Kerkhoff C, Voss A, Scholzen TE, Averill MM, Zanker KS, Bornfeldt KE: Novel insights into the role of S100A8/A9 in skin biology. Exp Dermatol, 2012; 21: 822-826.

90) Benedyk M, Sopalla C, Nacken W, et al: HaCaT keratinocytes overexpressing the $\mathrm{S} 100$ proteins S100A8 and S100A9 show increased NADPH oxidase and NF-kappaB activities. J Invest Dermatol, 2007; 127: 2001-2011.

91) Chamorro CI, Weber G, Gronberg A, Pivarcsi A, Stahle M: The human antimicrobial peptide LL-37 suppresses apoptosis in keratinocytes. J Invest Dermatol, 2009; 129: 937-944.

92) Ganguly D, Chamilos G, Lande R, et al: Self-RNA-antimicrobial peptide complexes activate human dendritic cells through TLR7 and TLR8. J Exp Med, 2009; 206: 1983-1994.

93) Lande R, Gregorio J, Facchinetti V, et al: Plasmacytoid dendritic cells sense self-DNA coupled with antimicrobial peptide. Nature, 2007; 449: 564-569.

94) Tewary P, de la Rosa G, Sharma N, et al: Beta-defensin 2 and 3 promote the uptake of self or $\mathrm{CpG}$ DNA, enhance IFN-alpha production by human plasmacytoid dendritic cells, and promote inflammation. J Immunol, 2013; 191: 865-874.

95) Koczulla R, von Degenfeld G, Kupatt C, et al: Recent insights into atopic dermatitis and implications for management of infectious complications: An angiogenic role for the human peptide antibiotic LL-37/hCAP-18. J Clin Invest, 2003; 111: 1665-1672.

96) Biedermann T: Dissecting the role of infections in atopic dermatitis. Acta Derm Venereol, 2006; 86: 99-109.

97) DaVeiga SP: Epidemiology of atopic dermatitis: A review. Allergy Asthma Proc, 2012; 33: 227-234.

98) Boguniewicz M, Leung DY: Recent insights into atopic dermatitis and implications for management of infectious complications. J Allergy Clin Immunol, 2010; 125: 4-13; quiz 14-15.

99) de Jongh GJ, Zeeuwen PL, Kucharekova M, et al: High expression levels of keratinocyte antimicrobial proteins in psoriasis compared with atopic dermatitis. J Invest Dermatol, 2005; 125: 1163-1173.

100) Hata TR, Kotol P, Boguniewicz M, et al: History of eczema herpeticum is associated with the inability to induce human beta-defensin (hBD) $-2, \mathrm{hBD}-3$ and cathelicidin in the skin of patients with atopic dermatitis. Br J Dermatol, 2010; 163: 659-661.

101) Nomura I, Goleva E, Howell MD, et al: Cytokine milieu of atopic dermatitis, as compared to psoriasis, skin prevents induction of innate immune response genes. J Immunol, 2003; 171: 3262-3269.

102) Wolk K, Kunz S, Witte E, Friedrich M, Asadullah K, Sabat R: IL-22 increases the innate immunity of tissues. Immunity, 2004; 21: 241-254.

103) Kopfnagel V, Harder J, Werfel T: Expression of 
antimicrobial peptides in atopic dermatitis and possible immunoregulatory functions. Curr Opin Allergy Clin Immunol, 2013; 13: 531-536.

104) Kisich KO, Carspecken CW, Fieve S, Boguniewicz M, Leung DY: Defective killing of Staphylococcus aureus in atopic dermatitis is associated with reduced mobilization of human beta-defensin-3. J Allergy Clin Immunol, 2008; 122: 62-68.

105) Grzanka A, Zebracka-Gala J, Rachowska R, Bozek A, Kowalska M, Jarzab J: The effect of pimecrolimus on expression of genes associated with skin barrier dysfunction in atopic dermatitis skin lesions. Exp Dermatol, 2012; 21: 184-188.

106) Harder J, Dressel S, Wittersheim M, et al: Enhanced expression and secretion of antimicrobial peptides in atopic dermatitis and after superficial skin injury. J Invest Dermatol, 2010; 130: 1355-1364.

107) Asano S, Ichikawa Y, Kumagai T, Kawashima M, Imokawa G: Microanalysis of an antimicrobial peptide, beta-defensin-2, in the stratum corneum from patients with atopic dermatitis. Br J Dermatol, 2008; 159: 97104.

108) Mallbris L, Carlen L, Wei T, et al: Injury downregulates the expression of the human cathelicidin protein hCAP18/LL-37 in atopic dermatitis. Exp Dermatol, 2010; 19: 442-449.

109) Kanda N, Watanabe S: Increased serum human betadefensin-2 levels in atopic dermatitis: Relationship to IL-22 and oncostatin M. Immunobiology, 2012; 217: $436-445$

110) Umehara $Y$, Kamata $Y$, Tominaga M, Niyonsaba F, Ogawa H, Takamori K: Cathelicidin LL-37 induces semaphorin 3A expression in human epidermal keratinocytes: Implications for possible application to pruritus. J Invest Dermatol, 2015; 135: 2887-2890.

111) Chen $X$, Takai T, Xie Y, Niyonsaba F, Okumura K, Ogawa H: Human antimicrobial peptide LL-37 modulates pro-inflammatory responses induced by cytokine milieus and double-stranded RNA in human keratinocytes. Biochem Biophys Res Commun, 2013; 433: 532-537.

112) Steinhoff M, Schauber J, Leyden JJ: New insights into rosacea pathophysiology: A review of recent findings. J Am Acad Dermatol, 2013; 69: S15-26.

113) Schwab VD, Sulk M, Seeliger S, et al: Neurovascular and neuroimmune aspects in the pathophysiology of rosacea. J Investig Dermatol Symp Proc, 2011; 15: 53-62.

114) Yamasaki K, Di Nardo A, Bardan A, et al: Increased serine protease activity and cathelicidin promotes skin inflammation in rosacea. Nat Med, 2007; 13: 975-980.

115) Yamasaki K, Kanada K, Macleod DT, et al: TLR2 expression is increased in rosacea and stimulates enhanced serine protease production by keratinocytes. J Invest Dermatol, 2011; 131: 688-697.

116) Gallo RL, Ono M, Povsic T, et al: Syndecans, cell surface heparan sulfate proteoglycans, are induced by a proline-rich antimicrobial peptide from wounds. Proc Natl Acad Sci U S A, 1994; 91: 11035-11039.

117) De Y, Chen Q, Schmidt AP, et al: LL-37, the neutrophil granule- and epithelial cell-derived cathelicidin, utilizes formyl peptide receptor-like 1 (FPRL1) as a receptor to chemoattract human peripheral blood neutrophils, monocytes, and T cells. J Exp Med, 2000; 192: $1069-1074$.
118) Meyer-Hoffert U, Schroder JM: Epidermal proteases in the pathogenesis of rosacea. J Investig Dermatol Symp Proc, 2011; 15: 16-23.

119) Jansen T, Krug S, Kind P, Plewig G, Messer G: Bsmi polymorphism of the vitamin $\mathrm{D}$ receptor gene in patients with the fulminant course of rosacea conglobata (rosacea fulminans). J Dermatol, 2004; 31: 244-246.

120) Peric M, Lehmann B, Vashina G, et al: UVB-triggered induction of vitamin D3 metabolism differentially affects antimicrobial peptide expression in keratinocytes. J Allergy Clin Immunol, 2010; 125: 746-749.

121) Schauber J, Gallo RL: The vitamin D pathway: A new target for control of the skin's immune response? Exp Dermatol, 2008; 17: 633-639.

122) Harper JC, Thiboutot DM: Pathogenesis of acne: Recent research advances. Adv Dermatol, 2003; 19: 1-10.

123) Vowels BR, Yang S, Leyden JJ: Induction of pro-inflammatory cytokines by a soluble factor of Propionibacterium acnes: Implications for chronic inflammatory acne. Infect Immun, 1995; 63: 3158-3165.

124) Trivedi NR, Gilliland KL, Zhao W, Liu W, Thiboutot DM: Gene array expression profiling in acne lesions reveals marked upregulation of genes involved in inflammation and matrix remodeling. J Invest Dermatol, 2006; 126: 1071-1079.

125) Nagy I, Pivarcsi A, Koreck A, Szell M, Urban E, Kemeny L: Distinct strains of Propionibacterium acnes induce selective human beta-defensin-2 and interleukin-8 expression in human keratinocytes through Tolllike receptors. J Invest Dermatol, 2005; 124: 931-938.

126) Chronnell CM, Ghali LR, Ali RS, et al: Human beta defensin-1 and -2 expression in human pilosebaceous units: Upregulation in acne vulgaris lesions. J Invest Dermatol, 2001; 117: 1120-1125.

127) Ortega MR, Ganz T, Milner SM: Human beta defensin is absent in burn blister fluid. Burns, 2000; 26: 724-726.

128) Milner SM, Ortega MR: Reduced antimicrobial peptide expression in human burn wounds. Burns, 1999; 25: 411-413.

129) Oono T, Huh WK, Shirafuji Y, Akiyama H, Iwatsuki K: Localization of human beta-defensin-2 and human neutrophil peptides in superficial folliculitis. $\mathrm{Br} \mathrm{J}$ Dermatol, 2003; 148: 188-191.

130) Kreuter A, Hyun J, Skrygan M, et al: Ultraviolet A1-induced downregulation of human beta-defensins and interleukin- 6 and interleukin- 8 correlates with clinical improvement in localized scleroderma. $\mathrm{Br} \mathrm{J}$ Dermatol, 2006; 155: 600-607.

131) Abiko Y, Jinbu Y, Noguchi T, et al: Upregulation of human beta-defensin 2 peptide expression in oral lichen planus, leukoplakia and candidiasis. An immunohistochemical study. Pathol Res Pract, 2002; 198: 537542.

132) Fitzgerald-Hughes D, Devocelle M, Humphreys H: Beyond conventional antibiotics for the future treatment of methicillin-resistant Staphylococcus aureus infections: Two novel alternatives. FEMS Immunol Med Microbiol, 2012; 65: 399-412.

133) Fjell CD, Hiss JA, Hancock RE, Schneider G: Designing antimicrobial peptides: Form follows function. Nat Rev Drug Discov, 2012; 11: 37-51.

134) Harvey AL, Edrada-Ebel R, Quinn RJ: The re-emergence of natural products for drug discovery in the genomics era. Nat Rev Drug Discov, 2015; 14: 111-129. 